Original research article

\title{
Structured integration of family planning curriculum: comparative assessment of knowledge and skills among new medical graduates in Ethiopia
}

\author{
Berhanu G. Gebremeskel a,b,*, Alula M. Teklu ${ }^{c}$, Lia T. Gebremedhin ${ }^{\mathrm{a}, \mathrm{b}}$, Solomon W. Beza ${ }^{\mathrm{a}}$, Tegbar Yigzaw ${ }^{\mathrm{d}}$, \\ Munir K. Eshetu ${ }^{a}$, Mengistu H. Damtew ${ }^{\text {a }}$, Yolanda R. Smith ${ }^{\text {a,b }}$
}

\footnotetext{
a Center for International Reproductive Health Training (CIRHT), University of Michigan, Ann Arbor, MI, 48109

b Department of Obstetrics and Gynecology, University of Michigan, Ann Arbor, MI, 48109

c St. Paul's Hospital Millennium Medical College, Addis Ababa, Ethiopia

d Jhpiego Ethiopia, Strengthening Human Resources for Health Project, Addis Ababa, Ethiopia
}

\section{A R T I C L E I N F O}

\section{Article history:}

Received 5 June 2017

Received in revised form 30 March 2018

Accepted 3 April 2018

\section{Keywords:}

Medical education

Contraception

Simulation

Training

LARC

Competency

\begin{abstract}
A B S T R A C T
Objective: The objective was to assess if structured integration of a comprehensive family planning (FP) training into a medical school curriculum improves FP knowledge and skill scores of medical interns.

Study design: We compared mean contraception knowledge scores of interns in a medical school with the integrated FP curriculum [intervention school] $(n=56)$ to interns at four conventional medical curriculum schools without structured reinforcement of FP content [control schools] $(n=161)$ in Ethiopia. A survey with 19 multiple choice contraception questions was administered. We also compared the mean contraception skills scores of the two groups at four Objective Structured Clinical Examination stations. The survey included selfreported number of contraception procedures and self-assessed competencies on a Likert scale.

Results: A total of 217 interns who have completed an Obstetrics and Gynecology rotation participated in the study. Interns from the intervention school reported performing substantially higher numbers of contraception procedures and rated themselves as being competent/highly competent across all procedures compared to the control schools ( $\mathrm{p}<.001$ for both). The mean knowledge score was significantly higher in the intervention school [13.1 vs. 8.7, difference 4.5, 95\% CI: (3.7-5.2), $\mathrm{p}<.001$ ]. The mean contraceptive implant insertion skill score was twofold higher for interns in the intervention school [22 points vs. 11, difference 10.7, 95\% CI: (8.6-12.8), $\mathrm{p}<.001$ out of a maximum possible point of 30]. Statistically significant differences in skill scores were also observed for intrauterine device IUD insertion [15 vs. $12, \mathrm{p}<.01]$ and implant removal [11 vs. 9, $\mathrm{p}=.01$ ].

Conclusion: A structured integration of family planning curriculum was associated with higher scores in knowledge, clinical skills and self-assessed competencies.

Implications: Integrating comprehensive family planning training in medical curriculum can lead to graduating physicians who are more competent to offer the full range of FP options.
\end{abstract}

(c) 2018 Elsevier Inc. All rights reserved.

\section{Introduction}

Across the globe, accessing the most effective family planning (FP) methods, especially long-acting reversible contraceptives (LARC), requires trained providers. However, studies from low- and middle-income countries (LMICs) suggest that medical students are often unprepared to provide these services because of misconceptions or lack of training [1-6]. This training gap delays the ability to address this important women's health need. Indeed, in Ethiopia, there is a high rate of unintended pregnancy [7], with an unmet contraceptive

\footnotetext{
* Corresponding author.

E-mail address: bgereme@med.umich.edu (B.G. Gebremeskel).
}

need of $22.3 \%$ and a low utilization of LARCs ( $8 \%$ for implants and $2 \%$ for IUDs) [8].

Limited provider knowledge results in few LARC insertions even when this contraceptive method is free $[9,10]$. An intervention study in Ethiopia demonstrated that LARC in-service training of healthcare providers increased election of LARC methods by threefold over 6 months [11]. This was also demonstrated in Zambia where over 33,000 women received an IUD (34\%) or a subdermal implant (66\%) in the 14 months after provider training [12]. Supplemental training after medical school, while successful, is likely less efficient, sustainable and cost-effective than structured training within medical school.

Medical education in FP is critical for preparing future providers and increasing access to LARC. Evidence suggests that education during clerkship experiences is an effective way to train medical students in 
contraception in the United States [13]. However, there is little information about effective strategies in Ethiopia and other LMICs. In Ethiopia, contraception training traditionally includes lectures during Obstetrics and Gynecology (Ob-Gyn) clerkship but without specific skill-focused FP exposure. Cognizant of this gap, competencies for all methods of reversible contraceptives were integrated into the medical school curriculum at St. Paul's Hospital Millennium Medical College (SPHMMC), Addis Ababa, in 2012, in collaboration with the Department of Ob-Gyn at the University of Michigan. Following this, the Center for International Reproductive Health Training (CIRHT) was established at the University of Michigan with the goal of decreasing maternal morbidity and mortality through effective preservice training of medical students in FP and abortion. The University of Michigan is providing support for the integration program through various faculty development initiatives in Ethiopia.

The objective of this study was to assess if structured integration of comprehensive FP training into a medical school curriculum improves FP knowledge and skills of interns. We also investigated potential factors associated with knowledge and skills (demographics, selfassessed competencies and reported number of procedures). We hypothesized that interns from the intervention site with the structured integrated curriculum (SPHMMC) have higher knowledge and skill scores compared to four control sites with conventional curriculum.

\section{Material and methods}

This study, conducted in five Ethiopian medical schools, compared the intervention school that implemented a structured FP curriculum since 2012 (SPHMMC, established in 2007) to four control schools with conventional curriculum (Jimma University, University of Gondar, Mekelle University and Bahir Dar University). Medical school in Ethiopia is 5 years ( 2 preclinical years, 2 clinical years and a 1-year rotating internship). The subjects for this study are all final-year interns who have completed their 3-month Ob-Gyn internship rotation (Fig. 1).

\subsection{Intervention site}

The structured integrated FP training at SPHMMC involved five FP didactic sessions during third year of medical school (three 1-h lectures, one tutorial and one seminar) and five simulation sessions during the fourth year to practice FP and abortion procedures [implant and IUD insertion and removal and manual vacuum aspiration (MVA)] under ObGyn faculty supervision. After a fourth-year qualifying exam, students complete a 1-year rotating internship before graduation. At the intervention site, interns had service rotations at SPHMMC's FP clinic for 1 week within their 10-week Ob-Gyn rotation, performing supervised LARC procedures (Fig. 1). Faculty used a standardized curriculum ensuring coverage of all essential content and minimizing any variability in the training. The faculty supervise the interns when doing LARC procedures. This paper reports FP outcomes and does not present the results of the comprehensive abortion care training.

\subsection{Control sites}

The four control medical schools have existed for at least 10 years. Their Ob-Gyn curriculum comprised $3 \mathrm{~h}$ of lectures on FP and comprehensive abortion care topics. There were no FP skill teaching in simulated or clinical settings, and no emphasis on students rotating through FP clinics during their internship. However, interns were expected to perform supervised MVAs in the management of patients with incomplete abortion during the gynecology rotation. They were not expected to place LARC devices or participate in family planning rotations during their internship year (Fig. 1).

\subsection{Primary outcome measures}

\subsubsection{Knowledge scores}

Knowledge was assessed through 19 context-based multiple choice questions (MCQs) on FP mechanism of action, side effect, complication management, safe method choice and counseling. Safety and management questions were based on clinical vignettes. Questions were pooled

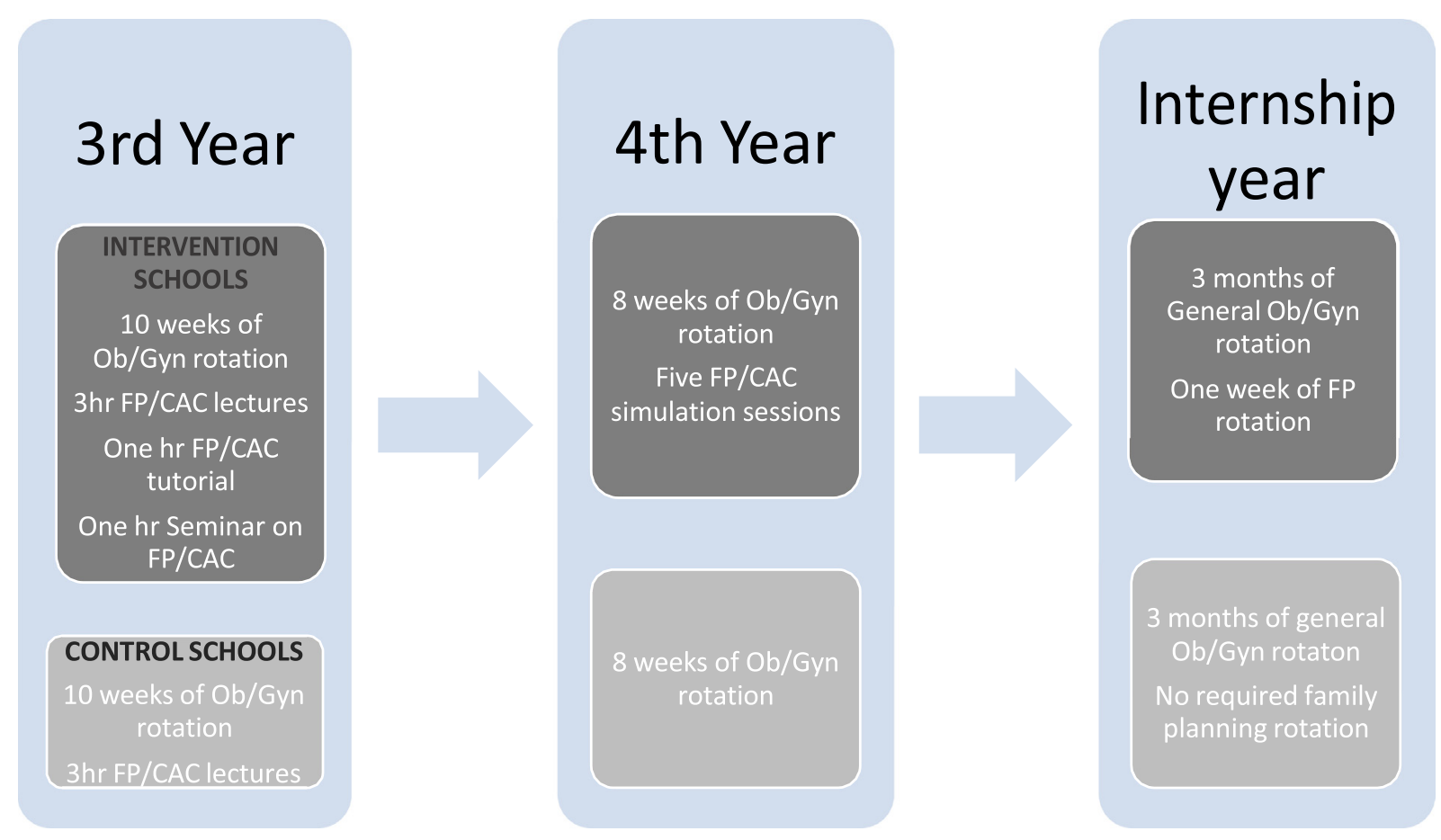

Fig. 1. Ob-Gyn rotations for clinical students and interns at intervention and control schools. CAC: comprehensive abortion care. 
from standardized FP training materials, reviewed and endorsed by a panel of national family planning curriculum experts who assessed the importance and difficulty level of each of the knowledge questions.

\subsubsection{Observed competence (skill) scores}

FP service providers trained in conducting Objective Structured Clinical Examinations (OSCEs) rated interns at four FP skill stations (implant insertion and removal, IUD insertion and FP counseling) using scales ( 0 2 ) for each portion of the skill/task ( 0 indicating not completed, 1 indicating partially performed, and 2 indicating completed). The OSCE raters were blinded to group status. Each of the four stations had 10 15 tasks, with the maximum possible score ranging from 20 to 30 per station. The counseling OSCE had 10 tasks that included building rapport, exploring patient's knowledge and desires, addressing misconception, providing tailored information, addressing medical eligibility, and discussing side effects and implementation challenges.

\subsection{Other measures, data collection tools and procedures}

\subsubsection{Perceived competence measures}

Participant's competency level in performing FP procedures as judged by themselves was assessed by Likert scale (not observed/not competent, somewhat competent, competent, and highly competent).

\subsubsection{Self-reported procedure number}

We collected the number of procedures students reported observing and/or performing during medical training (none, 1-2, 3-5, 6-10, 10 $20,>20)$.

After signing a written consent, interns completed the selfadministered demographic and perceived competence surveys, followed by MCQ knowledge questions. For each school, all participants completed the questions at the same place and time. The skills of the interns were then assessed using four manned OSCE stations. We obtained the simulation models (such as implant insertion models) from standardized FP training packages. All completed surveys and skill assessment checklists were reviewed for completeness. We performed double data entry into Access 2016 database and reviewed source documents to resolve discrepancies.

\subsection{Data analysis}

The intervention and control schools were compared using $\chi^{2}$ and/ or Fisher's Exact Test for categorical variables. For self-reported number of procedures and self-assessed competencies, we noted a number of zero cells and collapsed these groupings into relevant categories. For continuous variables (including knowledge scores and the four skills), we used two-sample Student's $t$ test and Wilcoxon rank-sum tests as appropriate to compare groups. An intern's knowledge score was computed as the sum of correct responses out of 19 MCQs, with a maximum possible of score of 19. For the four skills scores, each task component (rated 0,1 or 2) was summed across competencies to compute a total score for an individual intern. We calculated the mean score for each group to make comparisons using appropriate statistical tests ( $t$ test and/or Wilcoxon rank sum).

We fitted a series of multiple linear regression models to determine factors associated with scores in knowledge and the four skills. We initially examined bivariate associations by regressing these outcomes over specified covariates, including those variables with $\mathrm{p}$ value $<.05$ in subsequent regression models. We a priori specified clinically relevant variables (demographics, self-assessed competencies and number of procedures) for inclusion into the models. All statistical analyses were performed with Stata/SE Version 14.2. p values $<.05$ were considered significant. All analyses were done by deleting entries with missing outcome variables.

The research project was approved by the Ethiopian Public Health Institute Scientific and Ethical Review Committee. All consenting interns who completed a rotating internship in the Ob-Gyn department were eligible for inclusion. Each participant received 250 ETB ( US\$11) for their time. Financial incentive for the participating interns was provided through CIRHT funding.

\section{Results}

Of 248 eligible interns, 217 [93\% (56) in the intervention and 86\% (161) in the four control schools]) participated. Almost all who did not participate were not on site during study conduct, with only two refusals. The two groups had similar demographic characteristics with few exceptions (Table 1). The mean age of study participants was 25 years. Most participants were male, single, rural in background, ethnically Amhara or Oromo. The majority of interns were affiliated with Orthodox Christianity, based their ethical values on the Bible, and attended religious services at least once a month. Almost every participant in both groups (98.1\%) indicated that religion is very important in their lives. However, the control group had greater proportions of participants from Amhara ethnic group (51.9\% vs. 34\%) and Orthodox Christianity (74.5\% vs. $56.4 \%$ ) than the intervention group. Less than a

Table 1

Demographic characteristics of Ethiopian interns by type of FP curriculum ${ }^{\mathrm{a}}$

\begin{tabular}{|c|c|c|c|}
\hline \multirow[t]{2}{*}{ Characteristics } & \multirow{2}{*}{$\begin{array}{l}\text { Intervention } \\
(n=56) \\
\text { No. }(\%)\end{array}$} & \multirow{2}{*}{$\begin{array}{l}\text { Control } \\
(n=161) \\
\text { No. }(\%)\end{array}$} & \multirow[b]{2}{*}{ p value $^{\mathrm{b}}$} \\
\hline & & & \\
\hline \multicolumn{4}{|l|}{ Gender } \\
\hline Female & $11(19.6)$ & $21(13.0)$ & \multirow{2}{*}{.27} \\
\hline Male & $45(80.4)$ & $140(87.0)$ & \\
\hline \multicolumn{4}{|l|}{ Ethnic group } \\
\hline Amhara & $18(34.0)$ & $83(51.9)$ & \multirow[t]{4}{*}{.01} \\
\hline Oromo & $19(35.8)$ & $30(18.8)$ & \\
\hline Tigray & $3(5.7)$ & $20(12.5)$ & \\
\hline Others & $13(24.5)$ & $27(16.9)$ & \\
\hline Age: mean (SD) & $24.5(1.4)$ & $24.7(1.2)$ & .37 \\
\hline \multicolumn{4}{|l|}{ Marital status } \\
\hline Single, never in a relationship & $18(32.1)$ & $79(49.1)$ & \multirow[t]{3}{*}{.07} \\
\hline Single, ever in a relationship & $36(64.3)$ & $78(48.4)$ & \\
\hline Married/living together & $2(3.6)$ & $4(2.5)$ & \\
\hline \multicolumn{4}{|l|}{ Religion } \\
\hline Orthodox & $31(56.4)$ & $119(74.4)$ & \multirow[t]{4}{*}{.04} \\
\hline Muslim & $11(20.0)$ & 19 (11.9) & \\
\hline Protestant & $12(21.8)$ & $17(10.6)$ & \\
\hline Others & $1(1.8)$ & $5(3.1)$ & \\
\hline \multicolumn{4}{|l|}{ Religious service attendance } \\
\hline Approximately weekly & $23(41.8)$ & $80(49.7)$ & \multirow[t]{4}{*}{.17} \\
\hline Once or twice a month & $21(38.2)$ & $37(23.0)$ & \\
\hline A few times a year & $9(16.4)$ & $31(19.3)$ & \\
\hline $\begin{array}{l}\text { Never/no religious } \\
\text { preference }\end{array}$ & $2(3.6)$ & $13(8.1)$ & \\
\hline \multicolumn{4}{|l|}{ Importance of religion } \\
\hline Not important & $1(1.8)$ & $3(1.9)$ & \multirow[t]{3}{*}{.42} \\
\hline Important & $15(26.8)$ & $31(19.4)$ & \\
\hline Very important & $40(71.4)$ & $126(78.8)$ & \\
\hline \multicolumn{4}{|c|}{ Value system for ethical decision making } \\
\hline Bible & $36(64.3)$ & $113(70.6)$ & \multirow[t]{4}{*}{.63} \\
\hline Family values & $6(10.7)$ & $16(10.0)$ & \\
\hline Islam & $10(17.9)$ & $18(11.3)$ & \\
\hline Secular values & $4(7.1)$ & $13(8.1)$ & \\
\hline \multicolumn{4}{|l|}{ Rural } \\
\hline No & $32(57.1)$ & $80(49.7)$ & \multirow[t]{2}{*}{.36} \\
\hline Yes & $24(42.9)$ & $81(50.3)$ & \\
\hline \multicolumn{4}{|l|}{ Expect to practice in rural } \\
\hline No & $6(10.9)$ & $38(23.6)$ & \multirow[t]{2}{*}{.05} \\
\hline Yes & $49(89.1)$ & $123(76.4)$ & \\
\hline \multicolumn{4}{|l|}{ Career interest } \\
\hline Ob-Gyn & $8(14.8)$ & $39(24.2)$ & \multirow[t]{2}{*}{.18} \\
\hline Others & $46(85.2)$ & $122(75.8)$ & \\
\hline
\end{tabular}

a The intervention curriculum was an integrated, structured FP curriculum. The control curriculum was the traditional FP curriculum.

b Based on Pearson $\chi^{2}$ test. 
quarter of the interns aspire to become Ob-Gyns, and more than three quarters anticipate practicing in rural settings.

The number of reported contraception counseling and implant insertion and removal procedures per intern was higher in the intervention site compared to the control school (Table 2). The proportion of interns who reported inserting more than five contraceptive implants was $96.5 \%$ and $8.7 \%$ for the intervention and control site, respectively $(\mathrm{p}<.001)$. Reported number of IUD insertions was overall low, with $57 \%$ of interns in the intervention school reporting no IUD insertions vs. $79 \%$ in the control group.

Compared to the control site, a higher proportion of interns from the school with the integrated curriculum rated themselves as competent/ highly competent in performing implant insertions (96.4\% vs. $31.2 \%$ ) and implant removals (67.8\% vs. 28.2\%) ( $\mathrm{p}<.001$ for both) (Table 3 ). However, most interns $(>80 \%)$ in both groups rated their competence in IUD insertion and removal as not competent or somewhat competent, with no statistically significant difference ( $\mathrm{p}=.46$ and .53 , respectively). The majority of interns in both groups rated themselves competent or highly competent in contraception counseling, with no statistically significant difference between groups $(\mathrm{p}=.13)$.

The mean knowledge score was higher for intervention site interns compared to controls [13.1 vs. 8.7, difference in scores $4.5,95 \% \mathrm{CI}$ : (3.7-5.2)] (Table 4). The mean score for implant insertions was twofold higher for the intervention group [22 points vs. 11, difference in score 10.7, 95\% CI: (8.6-12.8), p<.001]. Statistically significant differences in scores were also observed for IUD insertion [(15 vs. 12), $\mathrm{p}<.01]$ and

Table 2

Ethiopian interns' self-reported number of contraception procedures performed by type of FP curriculum ${ }^{\mathrm{a}}$

\begin{tabular}{|c|c|c|c|}
\hline \multirow[t]{2}{*}{$\begin{array}{l}\text { Type of contraception } \\
\text { procedure self-reported }\end{array}$} & \multirow{2}{*}{$\begin{array}{l}\text { Intervention } \\
n=56 \\
\text { No. (\%) }\end{array}$} & \multirow{2}{*}{$\begin{array}{l}\text { Control } \\
n=161 \\
\text { No. (\%) }\end{array}$} & \multirow[b]{2}{*}{ p value ${ }^{b}$} \\
\hline & & & \\
\hline \multicolumn{4}{|c|}{ Number counseled on contraception } \\
\hline None & 0 & $5(3.1)$ & \multirow[t]{6}{*}{$<.01$} \\
\hline $1-2$ & 0 & $7(4.3)$ & \\
\hline $3-5$ & $1(1.8)$ & $38(23.6)$ & \\
\hline $6-10$ & 0 & $36(22.4)$ & \\
\hline $11-20$ & $6(10.7)$ & $32(19.9)$ & \\
\hline$>20$ & $49(87.5)$ & $43(26.7)$ & \\
\hline \multicolumn{4}{|c|}{ Number of contraceptive implants inserted } \\
\hline None & & $85(52.8)$ & \multirow[t]{6}{*}{$<.01$} \\
\hline $1-2$ & $2(3.6)$ & $47(29.2)$ & \\
\hline $3-5$ & 0 & $15(9.3)$ & \\
\hline $6-10$ & $3(5.4)$ & $11(6.8)$ & \\
\hline $11-20$ & $13(23.2)$ & $3(1.9)$ & \\
\hline$>20$ & $38(67.9)$ & 0 & \\
\hline \multicolumn{4}{|l|}{ Number of IUDs inserted } \\
\hline None & $32(57.1)$ & $128(79.5)$ & \multirow[t]{5}{*}{$<.01$} \\
\hline $1-2$ & $18(32.1)$ & $23(14.3)$ & \\
\hline $3-5$ & $6(10.7)$ & $4(2.5)$ & \\
\hline $6-10$ & 0 & $5(3.1)$ & \\
\hline $11-20$ & 0 & $1(0.6)$ & \\
\hline \multicolumn{4}{|c|}{ Number of contraceptive implants removed } \\
\hline None & $19(33.9)$ & $106(65.8)$ & \multirow{6}{*}{$<.01$} \\
\hline $1-2$ & $14(25.0)$ & 32 (19.9) & \\
\hline $3-5$ & $13(23.2)$ & $14(8.7)$ & \\
\hline $6-10$ & $5(8.9)$ & $8(5.0)$ & \\
\hline $11-20$ & $3(5.4)$ & 0 & \\
\hline$>20$ & $2(3.6)$ & $1(0.6)$ & \\
\hline \multicolumn{4}{|l|}{ Number of IUDs removed } \\
\hline None & $44(78.6)$ & $133(82.6)$ & \multirow[t]{6}{*}{.05} \\
\hline $1-2$ & $11(19.6)$ & $15(9.3)$ & \\
\hline $3-5$ & 0 & $9(5.6)$ & \\
\hline $6-10$ & 0 & $2(1.2)$ & \\
\hline $11-20$ & 0 & $2(1.2)$ & \\
\hline$>20$ & $1(1.8)$ & 0 & \\
\hline
\end{tabular}

\footnotetext{
a The intervention curriculum was an integrated, structured FP curriculum. The control curriculum was the traditional FP curriculum.

b $\mathrm{p}$ value based on $\chi^{2}$ /Fisher's Exact Test.
}

Table 3

Ethiopian interns' self-reported contraception competence by type of FP curriculum ${ }^{\mathrm{a}}$

\begin{tabular}{|c|c|c|c|}
\hline \multirow[t]{2}{*}{$\begin{array}{l}\text { Type self-reported } \\
\text { contraception competencies }\end{array}$} & $\begin{array}{l}\text { Intervention } \\
n=56\end{array}$ & $\begin{array}{l}\text { Control } \\
n=161\end{array}$ & \multirow[b]{2}{*}{$\mathrm{p}$ value ${ }^{\mathrm{b}}$} \\
\hline & No. (\%) & No. (\%) & \\
\hline \multicolumn{4}{|c|}{ Self-reported contraception counseling } \\
\hline Not competent & 0 & $5(3.1)$ & \multirow[t]{4}{*}{.13} \\
\hline Somewhat competent & $6(10.7)$ & $33(20.5)$ & \\
\hline Competent & $31(55.4)$ & $85(52.8)$ & \\
\hline Highly competent & $19(33.9)$ & $38(23.6)$ & \\
\hline \multicolumn{4}{|l|}{ Self-reported Implant insertion } \\
\hline Not competent & $1(1.8)$ & $61(38.1)$ & \multirow[t]{4}{*}{$<.01$} \\
\hline Somewhat competent & $1(1.8)$ & $49(30.6)$ & \\
\hline Competent & $19(33.9)$ & $41(25.6)$ & \\
\hline Highly competent & $35(62.5)$ & $9(5.6)$ & \\
\hline \multicolumn{4}{|l|}{ Self-reported IUD insertion } \\
\hline Not competent & $27(48.2)$ & $85(53.5)$ & \multirow[t]{4}{*}{.46} \\
\hline Somewhat competent & $18(32.1)$ & $53(33.3)$ & \\
\hline Competent & $10(17.9)$ & $16(10.1)$ & \\
\hline Highly competent & $1(1.8)$ & $5(3.1)$ & \\
\hline \multicolumn{4}{|l|}{ Self-reported Implant removal } \\
\hline Not competent & $6(10.7)$ & 75 (46.9) & \multirow[t]{4}{*}{$<.01$} \\
\hline Somewhat competent & $12(21.4)$ & $40(25.0)$ & \\
\hline Competent & $26(46.4)$ & 35 (21.9) & \\
\hline Highly competent & $12(21.4)$ & $10(6.3)$ & \\
\hline \multicolumn{4}{|l|}{ Self-reported IUD removal } \\
\hline Not competent & $27(48.2)$ & $92(58.6)$ & \multirow[t]{4}{*}{.53} \\
\hline Somewhat competent & $18(32.1)$ & $36(22.9)$ & \\
\hline Competent & $9(16.1)$ & $24(15.3)$ & \\
\hline Highly competent & $2(3.6)$ & $5(3.2)$ & \\
\hline
\end{tabular}

a The intervention curriculum was an integrated, structured FP curriculum. The contro curriculum was the traditional FP curriculum.

${ }^{\mathrm{b}} \mathrm{p}$ values based on $\chi^{2}$ or Fisher's Exact Test.

implant removal [(11 vs. 9), $\mathrm{p}=.01]$. There was a trend toward the control group of interns scoring higher on counseling skills (12 vs. 11 , $\mathrm{p}=.06)$.

Intervention group status was associated with knowledge score in the final model (Table 5). Interns from the school with the integrated curriculum scored 4.4 points higher in knowledge than those in the control curriculum.

For IUD insertion skills scores, the final model included group status and reported number of procedures (Table 5). The intervention group interns scored 3 points higher compared to the control group. Interns who reported more IUD insertions had higher IUD insertion skills scores. Being an intern from the school with the integrated curriculum was associated with higher implant insertion skills scores. No other factor was associated with implant insertion skills scores in the final model. The only factor that remained significant for implant removal skills scores was self-assessed competency in removing implants, with those rating themselves as somewhat competent, competent and highly competent scoring 3 points higher compared to those who reported rating themselves as not competent/did not observe. Group status was not associated with implant removal skills scores in the final model. In the multivariable model, no factor was associated with counseling skills scores.

\section{Discussion}

To meet reproductive health needs, it is critical to understand the effectiveness of relevant medical education training. This is one of the few studies to provide outcome information on a FP curriculum intervention in a LMIC. The significantly higher number of reported FP procedures performed during training at the intervention site indicates that the plan to increase exposure and experience in FP techniques was executed. Our study demonstrates that structured integration of comprehensive FP education into the medical school curriculum in Ethiopia was associated with higher knowledge scores in new interns compared to institutions without this curriculum intervention. We also found that 
Table 4

Ethiopian interns' mean contraception and knowledge (MCQs) and skills scores (OSCE stations) by type of FP curriculum ${ }^{\mathrm{a}}$

\begin{tabular}{|c|c|c|c|c|c|}
\hline \multirow{2}{*}{$\begin{array}{l}\text { Contraception } \\
\text { knowledge and } \\
\text { skills scores }\end{array}$} & \multicolumn{2}{|c|}{ Intervention $n=56$} & \multicolumn{2}{|c|}{ Control $n=161$} & \multirow[b]{2}{*}{$\mathrm{p}$ value $^{\mathrm{b}}$} \\
\hline & $\begin{array}{l}\text { Mean } \\
\text { score }\end{array}$ & $95 \% \mathrm{CI}$ & $\begin{array}{l}\text { Mean } \\
\text { score }\end{array}$ & $95 \% \mathrm{CI}$ & \\
\hline Knowledge $^{c}$ & 13.1 & $(12.1-14.1)$ & 8.7 & $(8.4-9.0)$ & $<.01$ \\
\hline Counseling $^{\mathrm{d}}$ & 10.6 & $(9.7-11.5)$ & 12.1 & $(11.2-12.9)$ & .06 \\
\hline Implant insertion ${ }^{\mathrm{e}}$ & 21.6 & $(19.9-23.2)$ & 10.9 & $(9.7-12.0)$ & $<.01$ \\
\hline IUD insertion $^{\mathrm{f}}$ & 15.3 & $(13.7-16.9)$ & 11.6 & $(10.4-12.8)$ & $<.01$ \\
\hline Implant removal $^{\mathrm{g}}$ & 10.5 & $(8.5-9.8)$ & 8.7 & $(7.9-9.5)$ & .01 \\
\hline
\end{tabular}

a The intervention curriculum was an integrated, structured FP curriculum. The control curriculum was the traditional FP curriculum.

b Based on two-sample Student's t test.

c Possible range of scores (0-19).

d Possible range scores (0-20).

e Possible range of scores (0-30).

Possible scores $(0-20)$

g Possible scores (0-20).

interns exposed to the FP curriculum displayed higher skill scores in IUD placement, implant placement and implant removal. The intervention group assignment, self-assessed competency score, as well as number of reported LARC procedure experiences during medical school were all associated with various skill scores.

The need to improve contraception knowledge, especially LARC, among medical students has been recognized in LMICs [1-6], but without documented effective strategies. In the United States, a prospective study of students at seven medical schools found that IUD knowledge increased significantly after completion of a clinical rotation in Ob-Gyn [13]. Team-based learning in FP showed similar increases in knowledge compared to a lecture-based curriculum and was associated with improved problem-solving skills [14]. In our intervention site, the combination of experiences resulted in higher knowledge scores. In fact, our

Table 5

Factors associated with contraception knowledge and skills scores among Ethiopian interns

\begin{tabular}{|c|c|c|c|c|}
\hline Variables & $\beta^{\mathrm{b}}$ coefficient & $95 \% \mathrm{CI}$ & p value & $N$ \\
\hline \multicolumn{5}{|c|}{ Factors associated with contraception knowledge scores ${ }^{c}$} \\
\hline Intervention group & 4.44 & $(3.53-5.35)$ & $<.01$ & 217 \\
\hline $\begin{array}{c}\text { Number counseled on } \\
\text { contraception }\end{array}$ & & & .996 & 217 \\
\hline$>20$ & 0.002 & $(-0.82$ to 0.82$)$ & .996 & 92 \\
\hline Reference $(<20)$ & & & & 125 \\
\hline \multicolumn{5}{|c|}{ Factors associated with implant insertion skills scores ${ }^{c}$} \\
\hline $\begin{array}{l}\text { Intervention group } \\
\text { Reference (control) }\end{array}$ & 10.70 & $(8.60-12.77)$ & $<.01$ & 217 \\
\hline \multicolumn{5}{|c|}{ Factors associated with IUD insertion skills scores ${ }^{c}$} \\
\hline Intervention group & 2.97 & $(0.68-5.25)$ & .01 & 217 \\
\hline \# IUD insertions & & & .03 & 217 \\
\hline $1-5$ & 3.22 & $(0.86-5.57)$ & $<.01$ & 51 \\
\hline$\geq 6$ & 1.69 & $(-4.21$ to 7.59$)$ & .57 & 6 \\
\hline Reference (none) & & & & 160 \\
\hline \multicolumn{5}{|c|}{ Factors associated with implant removal skills scores ${ }^{c}$} \\
\hline Intervention group & 0.90 & $(-0.66$ to 2.45$)$ & .26 & 217 \\
\hline $\begin{array}{l}\text { Self-reported competency in } \\
\text { implant removal }\end{array}$ & & & $<.01$ & \\
\hline Somewhat competent & 2.86 & $(1.20-4.51)$ & $<.01$ & 52 \\
\hline Competent & 2.60 & $(1.36-4.49)$ & $<.01$ & 61 \\
\hline Highly competent & 3.18 & $(0.96-5.40)$ & .02 & 22 \\
\hline Reference (not competent) & & & & 81 \\
\hline
\end{tabular}

a The intervention curriculum was an integrated, structured FP curriculum. The control curriculum was the traditional FP curriculum. The reference is the control group.

b The beta coefficients represent the estimated mean difference from each reference group in each of the models.

c All models were controlled for age and gender. There were no significant differences between these models and those without age and gender adjustment multivariable regression analyses demonstrated that only intervention group status was associated with knowledge scores.

Assessment of clinical skills can be challenging for both trainers and students. Skill evaluation can be successfully accomplished with direct observation through OSCEs for gynecology and surgical skills [15-18]. In our study, the intervention had an impact on skills in IUD insertion and implant insertion and removal, and less impact on counseling which had a trend toward higher scores in the control group compared to the intervention group of interns. The higher scores at the intervention site for IUD and implant skills likely reflect the skills that benefit most from the educational package, while counseling skills may be learned in several environments. Alternatively, perhaps increased emphasis and other teaching methods are needed to refine counselling skills. Interestingly, self-assessment by the interns was associated with their performance on the implant removal score, suggesting appropriate insight into this skill development. The ability of learners to accurately self-assess has been questioned [19], with some studies of gynecologic skills demonstrating that learners can self-assess with good reliability and validity $[16,20,21]$. Results regarding selfassessment were overall mixed, with self-assessed competency being the only factor associated with implant removal skill score.

Intervention group status was associated with higher implant insertion skills scores, while self-assessed competency was the only factor associated with implant removal skill score. The intervention group had reported practicing more implant insertions (96\% of intervention group interns vs. $9 \%$ control interns indicating doing six or more implant insertions). Although there was an association between number of implants inserted and implant insertion skills scores in the univariable model, adjusting for group status eliminated this association. We thus infer that group status above and beyond number of implant insertion procedures is associated with implant insertion skills scores.

For IUD insertions, the number of insertions was associated with skill score. This suggests that for some skills, repeated practice may be more important than for others. A previous study in midwifery students demonstrated increased level of comfort in providing IUD services in those randomly allocated to a 12-h simulation-based education program for IUD placement as compared to traditional education [22]. Our study shows that, for interns, integration of an FP curriculum with practice on simulation models and a clinical rotation was associated with higher experience level, higher knowledge and skills scores, and higher self-assessment of skills. While short-term training may be successful for practitioners who are already skilled or training in gynecologic procedures, this integrated FP curriculum during medical school, and prior to any medical specialization, may be particularly valuable for countries such as Ethiopia where general practitioners are often providers of a wide range of clinical services across the country which include FP services.

This study is strengthened by its large sample size but has some limitations. We did not collect baseline knowledge and skills, and therefore, information on changes over time is not available. It is expected that baseline knowledge and skills were likely similar between the intervention and control sites. In addition, the intervention could not be randomized to multiple sites because of resource limitations. However, demographic analysis indicates that the subjects at the intervention and control sites did not have significant differences in areas likely to impact results. It is possible that other inherent medical curricular differences may exist between the intervention and control schools that influence our outcome measures, but we were unable to account for these. As the number of procedures was self-reported, there could be a recall bias. We assume that this might not be differentially distributed between the two groups and influence the results. The raters for the OSCE were different between sites but were all trained by the same team and followed a standardized scoring scheme. Further work is needed to determine if the results of our study are generalizable to other settings.

In conclusion, an integrated FP curriculum was associated with higher scores in knowledge, clinical skills and self-assessed competency. 
It is anticipated that this will lead to graduating physicians who are more comfortable and competent to offer the full range of FP options, especially LARC. Further work is needed to determine if this will translate into increased access to contraceptive options for women in Ethiopia and how long the interns will retain these skills.

\section{Acknowledgments}

The authors would like to thank the following individuals for input in the design and/or conduct of the study: Senait Fisseha, M.D., J.D.; Balkachew Nigatu, M.D.; and Delayehu Bekele, M.D., M.P.H. Additionally, we would like to acknowledge the data collectors and assessors. This work was financially supported by an anonymous donor through the Center for International Reproductive Health Training (CIRHT) at the University of Michigan [Project Grant number N018416]. The funding source did not have any involvement in the study design, data collection, analysis and interpretation of data, writing of the manuscript and the decision to submit the article for publication.

\section{References}

[1] da Silva-Filho AL, Lira J, Rocha AL, Carneiro MM. Barriers and myths that limit the use of intrauterine contraception in nulliparous women: a survey of Brazilian gynaecologists. Postgrad Med J 2016:1-6. https://doi.org/10.1136/postgradmedj2016-134247.

[2] Hoffman SJ, Guindon GE, Lavis JN, Randhawa H, Becerra-Posada F, Boupha B, et al. Clinicians' knowledge and practices regarding family planning and intrauterine devices in China, Kazakhstan, Laos and Mexico. Reprod Health 2016; 13(1):1-12.

[3] Hogmark S, Klingberg-Allvin M, Gemzell-Danielsson K, Ohlsson H, Essen B. Medical students' knowledge, attitudes and perceptions towards contraceptive use and counselling: a cross-sectional survey in Maharashtra, India. BMJ Open 2013;3(12): e003739.

[4] Muganyizi PS, Ishengoma J, Kanama J, Kikumbih N, Mwanga F, Killian R, et al. An analysis of pre-service family planning teaching in clinical and nursing education in Tanzania. BMC Med Educ 2014;14:142.

[5] Saleem MD, Tahir F, Shah DA, Haider SS. Medical students' knowledge and perceptions regarding contraception in Karachi, Pakistan. J Fam Plann Reprod Health Care 2015;41(1):76

[6] Ugaz J, Banke K, Rahaim S, Chowdhury W, Williams J. Private providers' knowledge, attitudes and misconceptions related to long-acting and permanent contraceptive methods: a case study in Bangladesh. Contraception 2016;94 (5):505-11.

[7] Habte D, Teklu S, Melese T, Magafu MG. Correlates of unintended pregnancy in Ethiopia: results from a national survey. PLoS One 2013;8(12):e82987.

[8] ICF CSACE. Ethiopia Demographic and Health Survey 2016: Key Indicators Report Addis Ababa, Ethiopia, and Rockville, Maryland, USA. Available from http:// dhsprogram.com/pubs/pdf/PR81/PR81.pdf; 2016.

[9] Gutin SA, Mlobeli R, Moss M, Buga G, Morroni C. Survey of knowledge, attitudes and practices surrounding the intrauterine device in South Africa. Contraception 2011; 83(2):145-50.

[10] van Zijl S, Morroni C, van der Spuy ZM. A survey to assess knowledge and acceptability of the intrauterine device in the family planning services in Cape Town, South Africa. J Fam Plann Reprod Health Care 2010;36(2):73-8.

[11] Tilahun Y, Mehta S, Zerihun H, Lew C, Brooks MI, Nigatu T, et al. Expanding access to the intrauterine device in public health facilities in Ethiopia: a mixed-methods study. Glob Health Sci Pract 2016;4(1):16-28.

[12] Neukom J, Chilambwe J, Mkandawire J, Mbewe RK, Hubacher D. Dedicated providers of long-acting reversible contraception: new approach in Zambia. Contraception 2011;83(5):447-52.

[13] Bartz D, Tang J, Maurer R, Janiak E. Medical student intrauterine device knowledge and attitudes: an assessment of clerkship training. Contraception 2013;88(2): 257-62.

[14] Mody SK, Kiley J, Gawron L, Garcia P, Hammond C. Team-based learning: a novel approach to medical student education in family planning. Contraception $2013 ; 88(2)$ : 239-42.

[15] Goff BA, Lentz GM, Lee D, Houmard B, Mandel LS. Development of an objective structured assessment of technical skills for obstetric and gynecology residents. Obstet Gynecol 2000;96(1):146-50.

[16] Goff BA, Nielsen PE, Lentz GM, Chow GE, Chalmers RW, Fenner D, et al. Surgical skills assessment: a blinded examination of obstetrics and gynecology residents. Am J Obstet Gynecol 2002;186(4):613-7.

[17] Martin JA, Regehr G, Reznick R, MacRae H, Murnaghan J, Hutchison C, et al. Objective structured assessment of technical skill (OSATS) for surgical residents. Br J Surg $1997 ; 84(2): 273-8$.

[18] Reznick RK. Teaching and testing technical skills. Am J Surg 1993;165(3) 358-61.

[19] Gordon MJ. A review of the validity and accuracy of self-assessments in health professions training. Acad Med 1991;66(12):762-9.

[20] Mandel LS, Goff BA, Lentz GM. Self-assessment of resident surgical skills: is it feasible? Am J Obstet Gynecol 2005;193(5):1817-22.

[21] de Blacam C, O'Keeffe DA, Nugent E, Doherty E, Traynor O. Are residents accurate in their assessments of their own surgical skills? Am J Surg 2012;204(5): 724-31.

[22] Khadivzadeh T, Erfanian F. The effects of simulated patients and simulated gynecologic models on student anxiety in providing IUD services. Simul Healthc 2012;7 (5):282-7. 